Article

\title{
$\alpha$ D-Conotoxins in Species of the Eastern Pacific: The Case of Conus princeps from Mexico
}

\author{
Arisaí C. Hernández-Sámano ${ }^{1}$, Andrés Falcón ${ }^{1}$, Fernando Zamudio ${ }^{2}$, César V.F. Batista ${ }^{3}$, \\ Jesús Emilio Michel-Morfín ${ }^{4}$, Víctor Landa-Jaime ${ }^{4}$, Estuardo López-Vera ${ }^{5}$, Michael C. Jeziorski ${ }^{6}$ \\ and Manuel B. Aguilar 1,* \\ 1 Laboratorio de Neurofarmacología Marina, Departamento de Neurobiología Celular y Molecular, Instituto \\ de Neurobiología, Universidad Nacional Autónoma de México, Juriquilla, Querétaro 76230, Mexico \\ 2 Departamento de Medicina Molecular y Bioprocesos, Instituto de Biotecnología, Universidad Nacional \\ Autónoma de México, Cuernavaca, Morelos 62210, Mexico \\ 3 Laboratorio Universitario de Proteómica, Instituto de Biotecnología, Universidad Nacional Autónoma de \\ México, Cuernavaca, Morelos 62210, Mexico \\ 4 Departamento de Estudios para el Desarrollo Sustentable de Zonas Costeras, CUCSUR-Universidad de \\ Guadalajara, San Patricio-Melaque, Jalisco 48980, Mexico \\ 5 Laboratorio de Toxinología Marina, Unidad Académica de Ecología y Biodiversidad Acuática, Instituto de \\ Ciencias del Mar y Limnología, Universidad Nacional Autónoma de México, \\ Ciudad de México 04510, Mexico \\ 6 Unidad de Proteogenómica, Instituto de Neurobiología, Universidad Nacional Autónoma de México, \\ Juriquilla, Querétaro 76230, Mexico \\ * Correspondence: maguilar@unam.mx; Tel.: +52-(55)-5623-4043; Fax: +52-(442)-238-1043
}

Received: 12 June 2019; Accepted: 10 July 2019; Published: 12 July 2019

\begin{abstract}
Conus snails produce venoms containing numerous peptides such as the $\alpha$-conotoxins ( $\alpha$-CTXs), which are well-known nicotinic acetylcholine receptor (nAChR) antagonists. Thirty-eight chromatographic fractions from Conus princeps venom extract were isolated by RP-HPLC. The biological activities of 37 fractions $(0.07 \mu \mathrm{g} / \mu \mathrm{L})$ were assayed by two-electrode voltage clamp on human $\alpha 7$ nAChRs expressed in Xenopus laevis oocytes. Fractions F7 and F16 notably inhibited the response elicited by acetylcholine by $52.7 \pm 15.2 \%$ and $59.6 \pm 2.5 \%$, respectively. Fraction F7 was purified, and an active peptide (F7-3) was isolated. Using a combination of Edman degradation, mass spectrometry, and RNASeq, we determined the sequence of peptide F7-3: AVKKTCIRSTOGSNWGRCCLTKMCHTLCCARSDCTCVYRSGKGHGCSCTS, with one hydroxyproline $(\mathrm{O})$ and a free $\mathrm{C}$-terminus. The average mass of this peptide, 10,735.54 Da, indicates that it is a homodimer of identical subunits, with 10 disulfide bonds in total. This peptide is clearly similar to $\alpha \mathrm{D}$-CTXs from species of the Indo-Pacific. Therefore, we called it $\alpha \mathrm{D}-\mathrm{PiXXA}$. This toxin slowly and reversibly inhibited the ACh-induced response of the h $\alpha 7 \mathrm{nAChR}$ subtype, with an $\mathrm{IC}_{50}$ of $6.2 \mu \mathrm{M}$, and it does not affect the h $\alpha 3 \beta 2$ subtype at $6.5 \mu \mathrm{M}$.
\end{abstract}

Keywords: Cone snail; Conus princeps; $\alpha \mathrm{D}$-conotoxin; $\mathrm{nAChR}$; $\alpha 2 \mathrm{nAChR} ; \mathrm{h} \alpha 3 \beta 2 \mathrm{nAChR}$

Key Contribution: This is the first report of $\alpha \mathrm{D}-\mathrm{CTX}$ s from a species from the American Pacific.

\section{Introduction}

The nicotinic acetylcholine receptors (nAChRs) play important roles in neuronal signaling. They modulate the release of neurotransmitters, such as dopamine, norepinephrine, $\gamma$-amino butyric acid, and acetylcholine (ACh). Therefore, they are implicated in a variety of pathophysiologies [1]. $\mathrm{ACh}$ is released from the pre-synaptic terminal, and then it binds to the extracellular domain of 
post-synaptic nAChRs, which orthosterically leads to the opening of the transmembrane channel to mediate a cationic current [2]. Thus, the discovery or development of selective compounds that target different subtypes of nAChRs could yield novel molecular tools, and also provide additional therapeutic agents or leads for the treatment of neurological disorders [3]. The homomeric $\alpha 7 \mathrm{nAChR}$ is one of the predominant $\mathrm{nAChR}$ subtypes in the central nervous system. This $\mathrm{nAChR}$ subtype is mainly distributed in the hippocampus and the cerebral cortex, regions associated with learning and memory mechanisms [3]. Major human pathologies such as epilepsy, schizophrenia, myasthenic syndrome, and Parkinson's and Alzheimer's diseases are associated with a dysfunction of $\alpha 7 \mathrm{nAChRs}$, among other factors [3]. The $\alpha 7 \mathrm{nAChR}$ is also capable of inducing downstream signaling mechanisms in non-neuronal cells and is thought to be an ancestral form evolved in lower organisms that do not rely on fast excitatory mechanisms [4]. In humans, another common and predominant $\mathrm{nAChR}$ subtype is the $\alpha 3 \beta 2 \mathrm{nAChR}$, which is expressed in the cerebellum, dorsal root ganglia, and spinal cord, and is involved in pain sensation $[3,5]$.

Marine snails belonging to the genus Conus are venomous species distributed throughout tropical and subtropical waters. To date, more than 800 species of cone snails have been described, with more species likely remaining to be discovered [6]. They use fast-acting, and often paralyzing, venoms that are usually injected (small volumes, approximately $\leq 50 \mu \mathrm{L}$ ) into their prey or predator through a hypodermic needle-like modified radula tooth [4]. Molecular and phylogenetic studies have demonstrated that the evolution of envenomation strategies is typically a predatory rather than a defensive adaptation, but both are used by cone snails [7]. Conus venoms are complex mixtures of biologically active peptides. Mass spectrometry techniques have revealed that each species of cone snail produces from 200 to 1100, or even more, distinct toxins, termed conotoxins (CTXs), which may be neuroactive [8,9]. Typically, CTXs are small disulfide-rich peptides, between 10 and 40 residues in length $(<5 \mathrm{kDa})$, and containing two to four disulfide bonds, that act in synergy to induce the rapid immobilization of preys or deterrence of predators [3]. Disulfide bridges provide exceptional structural stability, enabling a tight interaction with their molecular targets, mainly ion voltage- or ligand-gated channels, transporters, and G-protein-coupled receptors [9]. CTXs are usually potent and selective, and their size is an advantage for cost-effective synthesis and makes them ideal neuropharmacological probes $[3,10]$.

Most of the CTXs that antagonize nAChR subtypes belong to the A-superfamily and they are known as alpha-conotoxins ( $\alpha$-CTXs) [11]. $\alpha$-CTXs usually present a type I cysteine framework (CC-C-C), or eventually a type IV (CC-C-C-C-C). However, CTXs targeting nAChRs have been found outside the A superfamily, including nine other superfamilies (B3, D, J, L, M, O1, S, T, and a yet unspecified family), with at least seven more cysteine frameworks [3]. Besides their well-known value as pharmacological tools and receptor labels, proposed applications of $\alpha$-CTXs include their use as pesticides, diagnostics, and therapeutics. Consequently, several $\alpha$-CTXs have been studied for these purposes [12]. Recently, a novel type of CTXs affecting nAChRs has been identified, the $\alpha \mathrm{D}$-CTXs. These toxins occur naturally as dimers of identical or different monomers (47-50 residues) with complex disulfide connections (10 disulfide bonds per dimer) and possessing varying levels of posttranslational heterogeneity associated with proline and glutamic acid conversion to hydroxyproline and $\gamma$-carboxyglutamic acid, respectively [2,13]. $\alpha$ D-CTXs block $\alpha 7$ and $\alpha 3 \beta 2$ [13] and $\alpha 9 \alpha 10$ [2] nAChRs.

$\alpha$-CTXs from Conus princeps have been identified from their coding nucleotide sequences and some of them probably target $\alpha 7 \mathrm{nAChR}$ [14]. Therefore, our aim was to identify $\alpha$-CTXs from C. princeps venom targeting human $\alpha 7 \mathrm{nAChRs}$, to purify one of them, and to characterize it chemically and electrophysiologically. However, during the biochemical and electrophysiological characterization, we discovered the first $\alpha \mathrm{D}$-CTX from a non-Indo-Pacific species, because of its apparent selectivity over human $\alpha 7 \mathrm{nAChR}$, it has potential for both neuroscience research and clinical applications. 


\section{Results}

\subsection{Peptidic Fractions of the C. princeps Venom and Determination of Activity on nAChRs}

Thirty-eight fractions were obtained from the crude venom duct extract of $C$. princeps by RP-HPLC (Figure 1), and the total protein obtained from this extract was $6.65 \mathrm{mg}$. All fractions, except the first one, were assayed at $0.07 \mu \mathrm{g} / \mu \mathrm{L}$, by the electrophysiological technique of two-electrode voltage clamp in Xenopus laevis oocytes. We identified nine active fractions that inhibited by $\geq 25.0 \%$ the ACh-induced response of the human $\alpha 7$ subtype, including two fractions, named F7 and F16, which inhibited this response by more than $50.0 \%$ (Figure 2 ).

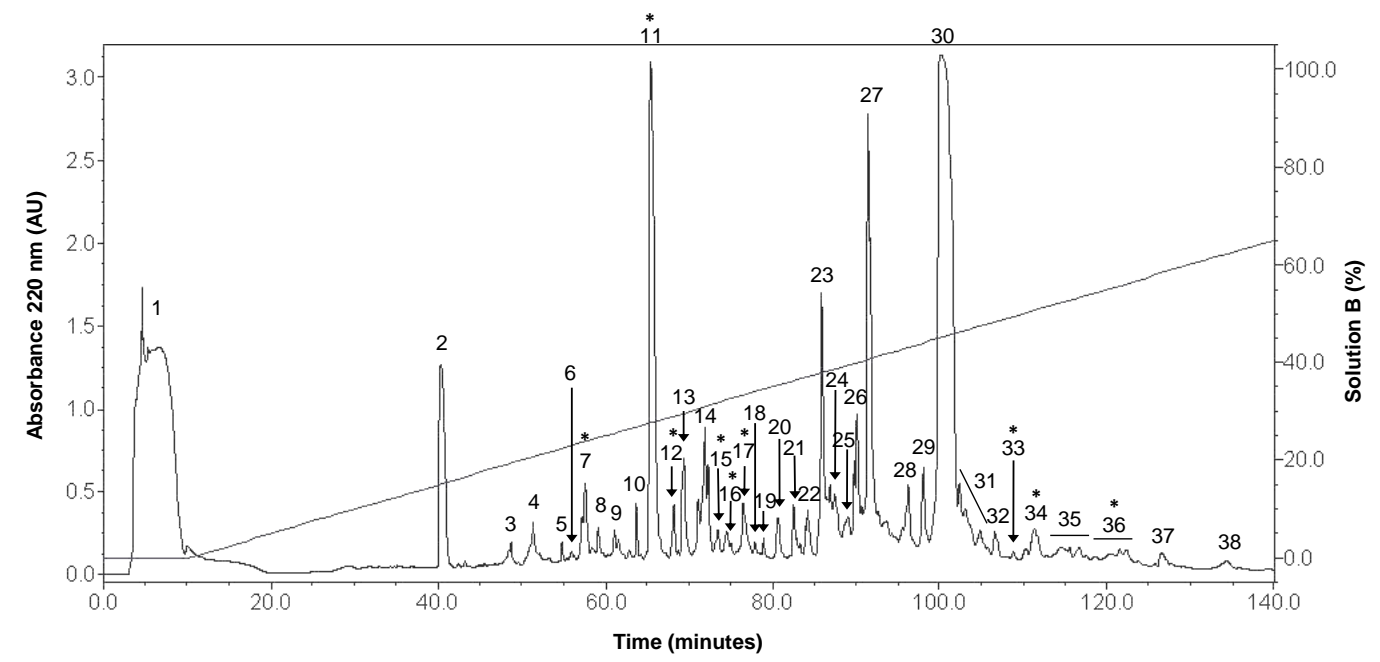

Figure 1. Fractionation by RP-HPLC of the C. princeps venom duct extract. An isocratic step at $0 \%$ Solution B for $10 \mathrm{~min}$, followed by a linear gradient of $0 \%$ to $100 \%(v / v)$ of Solution B, over 200 min was used at $1 \mathrm{~mL} / \mathrm{min}$. The absorbance was measured at $220 \mathrm{~nm}$. * Active fractions on human $\alpha 7$ nicotinic acetylcholine receptor ( $\mathrm{AAChR}$ ) inhibiting $\geq 25.0 \%$ the acetylcholine (ACh)-induced response.

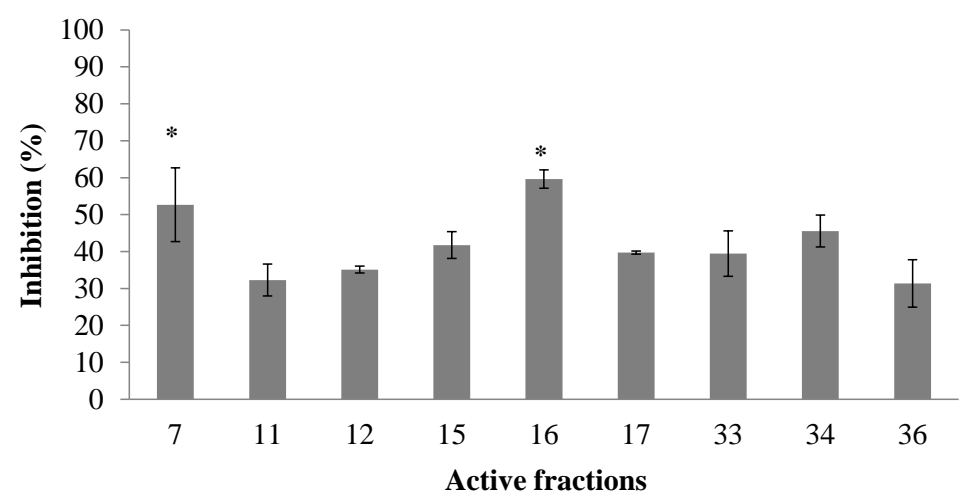

Figure 2. Active peptidic fractions (at $0.07 \mu \mathrm{g} / \mu \mathrm{L}$ ) from $C$. princeps venom on human $\alpha 7 \mathrm{nAChRs.}$ Experiments were performed at least 3 times and the values averaged. *Active fractions on h $\alpha 7 \mathrm{nAChRs}$ inhibiting $\geq 50.0 \%$ the ACh-induced response.

Fractions F7 and F16 represented 2.2\% and 1.0\% of protein, respectively, of the extracted venom from C. princeps. Fraction F7 blocked the ACh-induced response by $52.7 \pm 15.2 \%$ (Figure 3a), while fraction F16 blocked 59.6 = 2.5\% (Figure 3b), and both effects were slowly reversible. Fraction F7 was obtained in sufficient quantity for further purification and analysis, but this was not the case for fraction F16. 


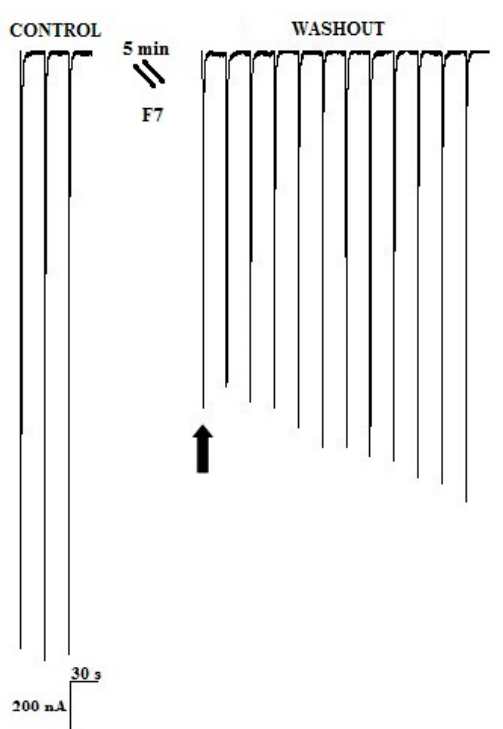

(a)

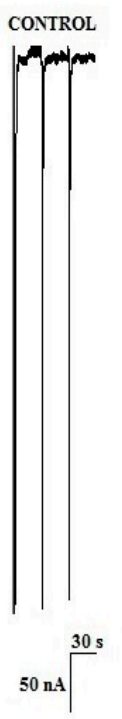

(b)

Figure 3. Representative current traces displaying the effect of active peptidic fractions (at $0.07 \mu \mathrm{g} / \mu \mathrm{L})$ from C. princeps venom on human $\alpha 7$ nAChRs. (a) F7 fraction; (b) F16 fraction.

\subsection{Purification of an Active Peptide of C. princeps Venom and Determination of Activity on $n A C h R s$}

As mentioned above, within the nine identified active peptidic fractions of the C. princeps venom, fraction F7 was selected, due to its favorable combination of potency and relative abundance, for further purification by RP-HPLC (Figure 4a). The biological activity of the two-step-purified active peptide, named F7-3 (Figure 4 b), was assessed once more by two-electrode voltage clamp recordings in oocytes. F7-3 peptide (at $0.07 \mu \mathrm{g} / \mu \mathrm{L}$ ) inhibited $55.4 \pm 15.2 \%$ the ACh-induced response on $\mathrm{h} \alpha 7 \mathrm{nAChRs}$ and its effect was slowly reversible, returning to the initial activity $21 \mathrm{~min}$ after (only 18 ACh-pulses shown in Figure 5a). In contrast, at the same concentration, this peptide did not significantly inhibit the ACh-induced response on $h \alpha 3 \beta 2 \mathrm{nAChRs}(n=3,6.7 \pm 3.1 \%)$ (Figure $5 \mathrm{~b})$. Therefore, we determined the half-maximal inhibitory concentration $\left(\mathrm{IC}_{50}\right)$ on h $\alpha 7 \mathrm{nAChRs}$, which was found to be $6.2 \mu \mathrm{M}$ (95\% confidence interval: $4.6 \mu \mathrm{M}-8.2 \mu \mathrm{M}$ ) (Figure 6).

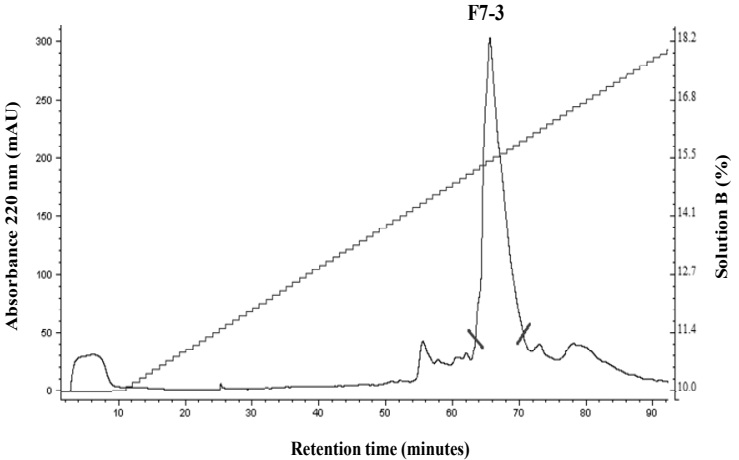

(a)

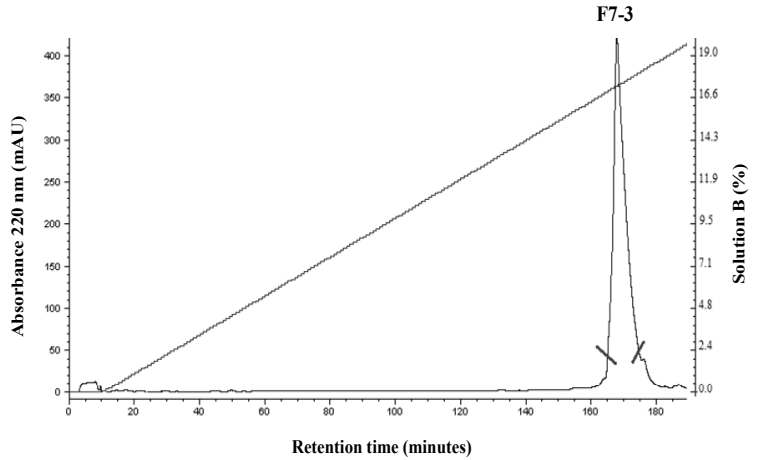

(b)

Figure 4. Purification of an active peptide of C. princeps venom by RP-HPLC. (a) F7 fraction: after an isocratic step at $10 \%$ Solution B for $10 \mathrm{~min}$, followed by a linear gradient of $10 \%$ to $30 \%(v / v)$ of Solution B, over $200 \mathrm{~min}$, at $1 \mathrm{~mL} / \mathrm{min}$ was used. (b) F7-3 peptide: after an isocratic step at $0 \%$ Solution B for $10 \mathrm{~min}$, followed by a linear gradient of $0 \%$ to $20 \%(v / v)$ of Solution B, over $200 \mathrm{~min}$, at $0.8 \mathrm{~mL} / \mathrm{min}$ was used. The absorbance was measured at $220 \mathrm{~nm}$. Only the F7-3 peptide collected between the diagonal lines was used for further analyses. 


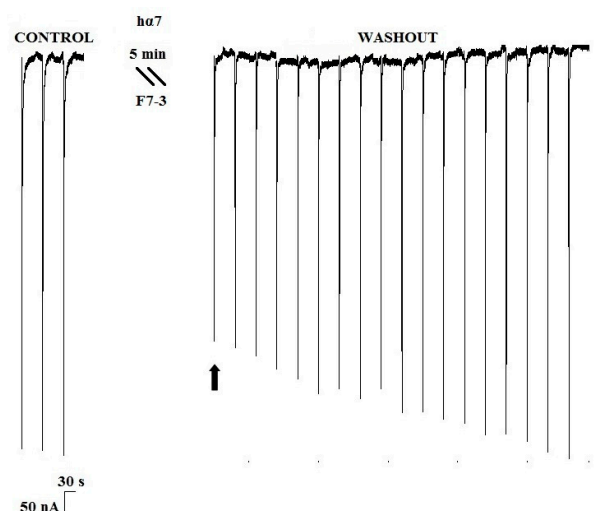

(a)
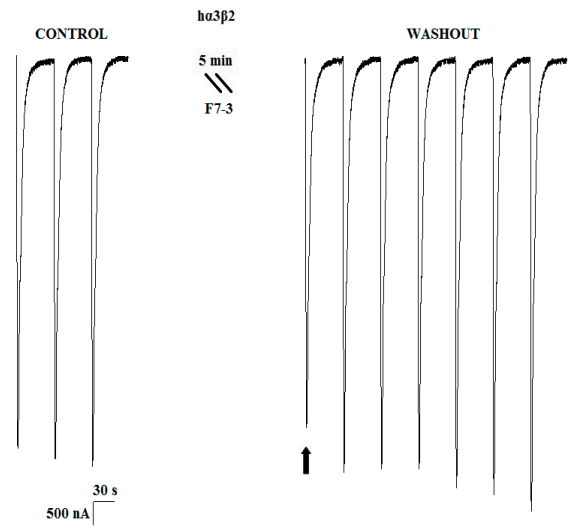

(b)

Figure 5. Representative current traces displaying the effect of the purified F7-3 peptide $($ at $0.07 \mu \mathrm{g} / \mu \mathrm{L})$ of $C$. princeps venom on two human nAChR subtypes. (a) h $\alpha 7(n=4)$; and (b) h $\alpha 3 \beta 2(n=3)$.

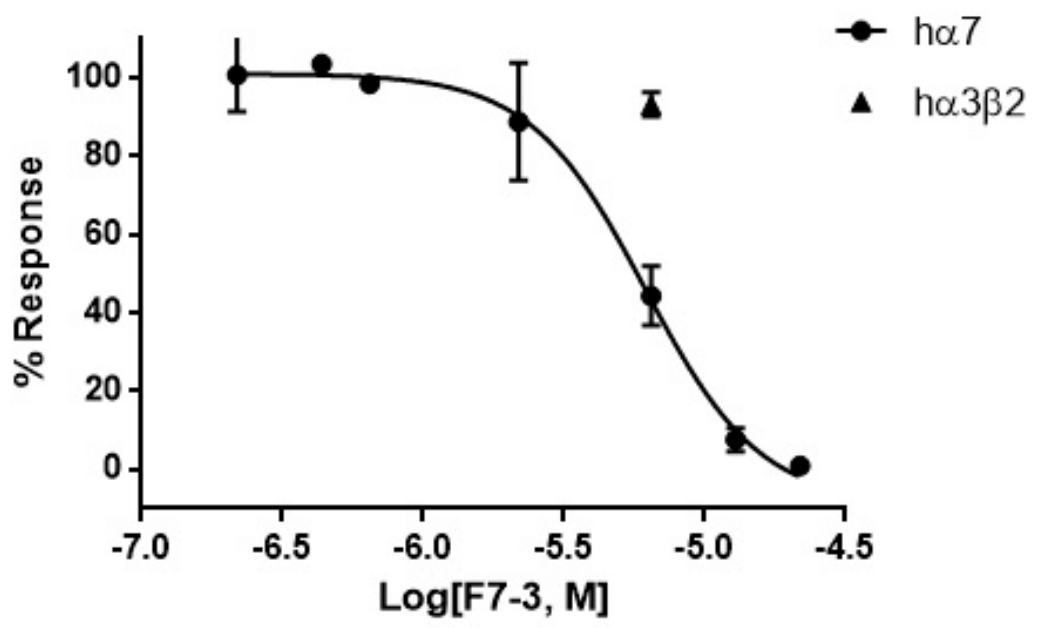

Figure 6. Concentration-response curve for the inhibition of human $\alpha 7 \mathrm{nAChRs}$ (circles) expressed in Xenopus laevis oocytes by the purified F7-3 peptide of $C$. princeps venom. The $\mathrm{IC}_{50}$ is $6.2 \mu \mathrm{M}$. The effect over human $\alpha 3 \beta 2$ (triangles) at $6.5 \mu \mathrm{M}$ is also shown.

\subsection{Molecular Mass and Amino Acid Sequence of the Purified Peptide}

The molecular mass of the purified F7-3 peptide was determined by ESI-MS without reduction and alkylation. A series of major $\mathrm{m} / \mathrm{z}$ average signals of $1085.96,1097.36$, and $1108.76(\mathrm{z}=10)$ was obtained; also, another series of major average $\mathrm{m} / \mathrm{z}$ signals with $\mathrm{z}=9$ was observed: $1193.95,1206.51$, $1219.18,1231.96,1244.62$, and 1248.62 (Figure 7a). When deconvoluted, these signals correspond to average masses of 10,735.54, 10,850.54, 10,963.55, 11,078.53, and 11,192.53 Da (Figure 7b). The lowest mass suggests that F7-3 peptide is composed of $\sim 98$ amino acid residues, assuming an average residue mass of $110 \mathrm{Da}$. The difference between any pair of consecutive masses ( 114 Da) indicates that, with the exception of the first species, the other are trifluoroacetic acid adducts of this species, as was first observed by Loughnan et al. [13].

By automated Edman degradation, a 32-residue sequence was obtained (Figure 8). Hydroxy-Pro (O) was present at position 11. At positions 6, 18, 19, 24, 28, 29, and 31, blank cycles (" $X$ ") were observed that likely correspond to Cys residues. Given this latter assumption, the theoretical average mass of this sequence is $3542.25 \mathrm{Da}$, according to Peptide Mass Calculator of the Mass Spectrometry and Biotechnology Resource of IonSourcesm mass spectrometry educational resource website [15], considering three disulfide bonds, one free Cys, one hydroxy-Pro residue, and a free 
C-terminus. This value is $7193.29 \mathrm{Da}$ lower than the average mass of the native molecule $(10,735.54 \mathrm{Da})$, which indicates that the sequence was not completely determined by $\sim 66$ residues.

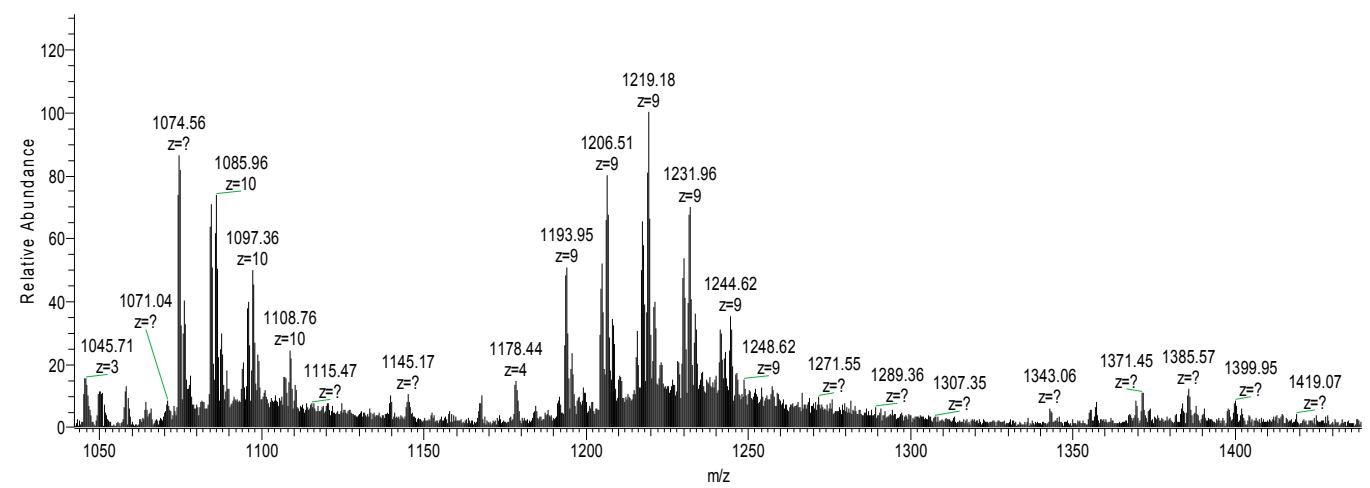

(a)

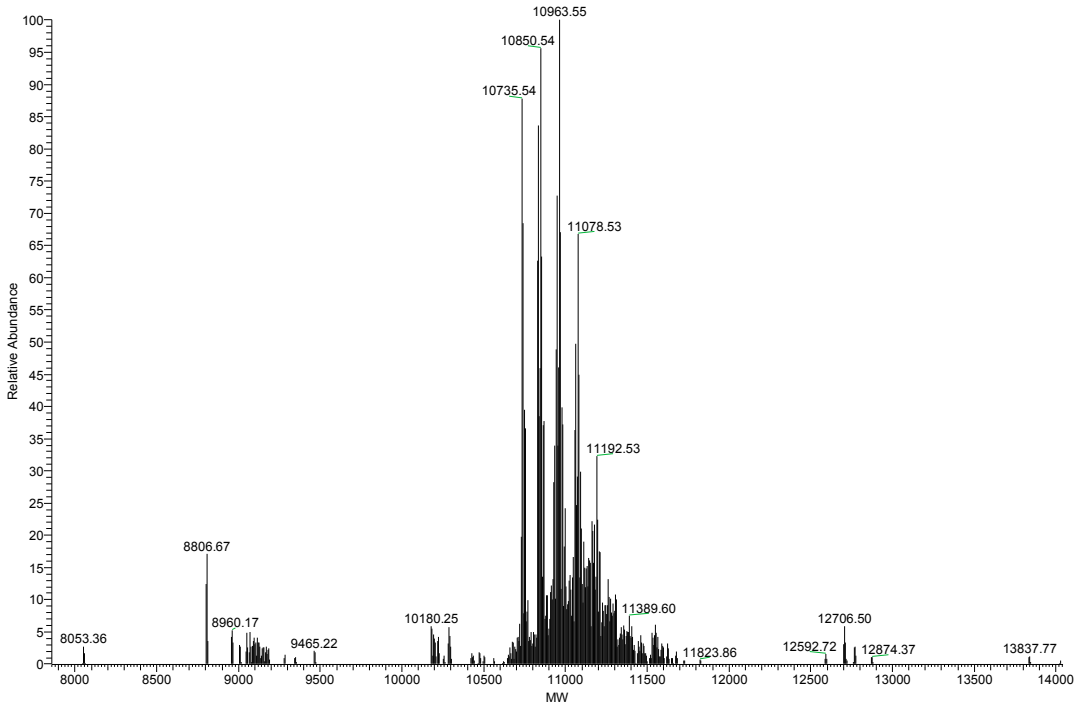

(b)

Figure 7. (a) Original mass spectrum of the native purified F7-3 peptide from C. princeps venom, the $\mathrm{m} / \mathrm{z}$ signal (assuming $\mathrm{z}=10$ ) at 1074.56 corresponds to an average mass of $10,735.50 \mathrm{Da}$, which agrees very well with the $\mathrm{m} / \mathrm{z}$ signal $(\mathrm{z}=9)$ at 1193.95 which corresponds to an average mass of 10,735.54 Da. "?" denotes that the charge of the ion was not automatically determined by the software. (b) Deconvoluted mass spectrum of the native purified F7-3 peptide from C. princeps venom.

Figure 8. Top line, sequence of the purified F7-3 ( $\alpha$ D-PiXXA) peptide from C. princeps obtained by automated Edman degradation; $\mathrm{O}$ is hydroxy-Pro. Bottom line, sequence TR34549_4_2 from the transcriptome of $C$. princeps venom duct; ${ }^{*}$ indicates identical residues at the same position.

The BLASTP similarity search revealed 25 significant hits $\left(E\right.$ value $\left.\leq 1 \times 10^{-4}\right)$ to the F7-3 toxin; except for "conopeptide Mi039 [Conus miles]" the distinct annotations of these hits identify them as $\alpha$ D-conotoxins (data not shown). These toxins are covalent dimers of identical or similar polypeptide chains of $\sim 50$ residues containing 10 disulfide bonds in total $[2,13,16,17]$, with two disulfide bonds linking the monomers [2]. 
Thus, we decided to compare the partial sequence of toxin F7-3, now renamed to $\alpha \mathrm{D}-\mathrm{PiXXA}$, to the predicted mature $\alpha$-D-conotoxin identified in the $C$. princeps venom duct transcriptome (transcript TR34549_4_2) [18] (to be published). It should be mentioned that the identities of the three last residues identified by automated Edman degradation are not totally reliable, due to the extremely low yield after 30-32 cycles. This comparison revealed a perfect match for 30 out of the 32 residues chemically identified, up to position 30 (Figure 8). This result strongly suggests that the sequence identified by RNASeq codes for that of the purified toxin.

Therefore, to verify this, we calculated the theoretical average mass of the sequence identified by RNASeq, considering one hydroxy-Pro residue for each monomer (directly observed by chemical sequencing of the purified F7-3 toxin), a free C-termini (deduced from the C-terminal sequence of the precursor identified by RNASeq) [18], and assuming 10 disulfide bonds (as the data from other researchers indicate $[2,13,16,17]$. This calculation yielded a value of $10,736.48 \mathrm{Da}$, which is in very good agreement with the experimental average mass of the intact toxin $(10,735.54 \mathrm{Da})$. Thus, we conclude that we have established the complete sequence of toxin $\alpha \mathrm{D}-\mathrm{PiXXA}$, which consists of a homodimer of two 50-residue chains, each containing a hydroxy-Pro residue and ten disulfide bridges in total [2].

\section{Discussion}

This work continues the study of the venom components of Conus princeps, a worm-hunter of the Eastern Pacific, from which one toxin, $\gamma$-CTX PiVIIA, has been recently purified and characterized at the chemical and electrophysiological levels $[19,20]$. Other toxins from this species have been identified by RT-PCR and transcriptomics $[14,18,21]$. Considering that most of the $\alpha \mathrm{A}-\mathrm{CTX}$ s identified by RT-PCR from $C$. princeps are predicted to target $\alpha 7 \mathrm{nAChRs}$ (but also $\alpha 3 \beta 2$ and other neuronal subtypes) [14], and the potential implications of $\alpha 7 \mathrm{nAChRs}$ antagonists to treat cancer, and cardiac and renal disorders [22], in this study we aimed to detect, purify, and characterize, toxins with activity at human $\alpha 7 \mathrm{nAChRs}$ from the venom of this species. Our identification of this activity in $24.3 \%$ (nine out of 37) of the venom fractions suggests a relevant role of $\alpha$-CTX targeting an $\alpha 7$-like subtype in predators and/or prey.

There are reports on short (containing four Cys residues) $\alpha \mathrm{A}-\mathrm{CTX}$ s inhibiting human $\alpha 7 \mathrm{nAChRs}$ from molluscivorous and piscivorous Conus species, for example, $\alpha$-PnIA and $\alpha$-PeIA of C. pennaceus and C. pergrandis, respectively [23-25]. In the case of worm-hunting species, there are short $\alpha \mathrm{A}-\mathrm{CTX} \mathrm{s}$ that inhibit the human $\alpha 7$ subtype, such as $\alpha$-ImI, $\alpha$-ImII, $\alpha$-RegIIA, and $\alpha$-LsIA [26-28], but there is also one long toxin belonging to the D-superfamily that inhibits human $\alpha 7$ nAChRs: $\alpha$ D-GeXXA [2].

The use of human $\alpha 7 \mathrm{nAChRs}$ in biological screening assays is relevant due to the potential application of $\alpha$-CTXs as potential drugs, or leads for them, for human disease treatments [22]. In this sense, it should be pointed out that studies using both rat and human nAChRs have been revealed important differences in selectivity of some $\alpha$-CTXs for several subtypes of these receptors [3]. For example, Yu et al. [29] compared the effects of $\alpha$-CTX analogues [K11A]TxIB and [H5D]RegIIA over rat and human $\alpha 7 \mathrm{nAChRs}$ and found that they are much more potent on the rat than on the human receptor. However, it should be pointed out that other studies have shown differences between human and rat subtypes $\alpha 9 / \alpha 10$ (for toxins RgIA [30] and Vc1.1 [31]) and $\alpha 3 \beta 2$ (for toxin RegIIA and its more potent analog [N11A, N12A]-RegIIA [32]). Interestingly, in all these cases, the affinity is higher for the rat subtypes, which has essential implications on the extrapolation of results obtained with rat $\mathrm{nAChRs}$ for applications related not only to the study of basic questions on the function of $\alpha 7 \mathrm{nAChRs,}$ but also to the treatment of human diseases.

As mentioned above, there are only two reports on $\alpha$-CTXs from $C$. princeps at the protein level and they refer to the same peptide with activity over two different molecular targets $[19,20]$. Therefore, in this work, we isolated two venom duct extract fractions (F7 and F16) that inhibited $\geq 50.0 \%$ the ACh-induced response of the h $\alpha 7 \mathrm{nAChR}$ subtype, and purified and characterized the least scarce of the two most potent fractions. The purified peptide (F7-3) significantly inhibited the ACh-induced response of the $h \alpha 7$ subtype with a very slowly reversible effect and an $\mathrm{IC}_{50}=6.2 \mu \mathrm{M}$, whereas it did 
not significantly affect the h $\alpha 3 \beta 2$ at $6.5 \mu \mathrm{M}$, which suggests that, regarding these two subtypes, it can be considered to be selective for h $\alpha 7 \mathrm{nAChRs}$. However (please, see below), it might also affect the $\mathrm{h} \alpha 9 / \alpha 10$.

The amino acid sequence of this toxin (partially determined by chemical sequencing, but confirmed by RNAseq and mass spectrometry), unexpectedly, but undoubtedly, revealed that it is an $\alpha \mathrm{D}-\mathrm{CTX}$, and, indeed, the first $\alpha$ D-CTX isolated from a species of the Eastern Pacific, $\alpha$ D-PiXXA.

The short and long $\alpha$-CTXs previously mentioned (PnIA, ImI, ImII, RegIIA, LsIA, and GeXXA) inhibit the $h \alpha 7$ subtype with higher affinity than $\alpha \mathrm{D}-\mathrm{PiXXA}[2,23,24,27,28]$. However, an interesting feature of the $\alpha \mathrm{D}$-CTX characterized in the present work is that it dissociates from the receptor significantly more slowly ( 21 min after starting the washout procedure, Figure 5 ) than most of the other toxins, with the exception of $\alpha$-CTX LsIA (15 min after [28]).

A few $\alpha$ D-CTXs from species of the Indo-Pacific (all of them vermivorous) have been characterized at the electrophysiological level: $\alpha \mathrm{D}-\mathrm{VxX} \mathrm{XIB}$ (currently named $\alpha \mathrm{D}-\mathrm{VxXXB}$ ) from Conus vexillum [13], $\alpha \mathrm{D}-\mathrm{Ms}$ from Conus mustelinus, and $\alpha \mathrm{D}-\mathrm{Cp}$ from Conus capitaneus [17], inhibit the $\alpha 7$ subtype with the highest affinity $\left(\mathrm{EC}_{50}\right)$, but also inhibit $\alpha 3 \beta 2$ and other $\mathrm{nAChRs} \mathrm{subtypes} \mathrm{with} \mathrm{clearly} \mathrm{lower} \mathrm{affinities.}$ Nevertheless, it should be pointed out that the effects of all these toxins have been assessed only over rat subtypes. Interestingly, $\alpha \mathrm{D}-\mathrm{GeXXA}$ from $C$. generalis has been shown to inhibit the human $\alpha 9 / \alpha 10$ subtype with higher affinity than the human $\alpha 7$ subtype [2]. Although the effect over the rat $\alpha 9 \alpha 10$ subtype was highest among six rat $(\alpha 9 \alpha 10, \alpha 3 \beta 2, \alpha 3 \beta 4, \alpha 1 \beta 1 \delta \varepsilon, \alpha 4 \beta 2$, and $\alpha 4 \beta 4)$ and two human ( $\alpha 9 \alpha 10$ and $\alpha 7)$ subtypes, the effect over the rat $\alpha 7$ subtype was not determined [2]. Therefore, this opens the question that other $\alpha \mathrm{D}$-conotoxins might have higher affinity for $\alpha 9 \alpha 10$ than for $\alpha 7$ (from human and/or rat). Unfortunately, due to the availability of natural peptide, this question could not be answered for $\alpha \mathrm{D}-\mathrm{PiXXA}$ (this work), and it was not addressed for toxins $\alpha \mathrm{D}-\mathrm{VxXXB}$ [13], and $\alpha \mathrm{D}-\mathrm{Ms}$ and $\alpha \mathrm{D}-\mathrm{Cp}$ [17].

According to the most recent molecular phylogeny of cone snails [33], $\alpha \mathrm{D}$-conotoxins have been characterized from species belonging only to six worm-hunting Conus subgenera: Rhizoconus (vexillum, capitaneus, mustelinus, miles, and rattus) [13,17,34,35], Strategoconus (vitulinus, generalis, planorbis) [2,16,35], Elisaconus (litteratus), Stephanoconus (imperialis), Splinoconus (tribblei) [35], and Ductoconus (princeps; this work). Interestingly, $\alpha \mathrm{D}$-conotoxins were not detected in any of the four piscivorous and two molluscivorous species studied by RT-PCR [34]. However, it should be pointed out that they were not detected in species later shown to express them, such as Strategoconus generalis [2], Stephanoconus imperialis, Elisaconus litteratus, and Rhizoconus miles [35]. The subgenera in which $\alpha \mathrm{D}$-conotoxins have been identified are early- (Stephanoconus and Strategoconus), intermediate(Ductoconus, Splinoconus, and Rhizoconus) and late-diverging (Elisaconus) among the Conus genus [33], which indicates that $\alpha \mathrm{D}-\mathrm{CTX}$ s are important members of the cone snails arsenal that have episodically evolved in this genus, although the possibility that they might be products of evolutionary convergence cannot be discarded [35]. However, the high sequence identity among the whole precursors (signal peptide, propeptide, and mature toxin) of the $\alpha \mathrm{D}$-conotoxins characterized so far (Figure $8 \mathrm{~B}$ ), suggests that convergence is not likely. Although the $\alpha \mathrm{D}$-conotoxins from the worm-hunters of the Indo-Pacific are all clearly major components of venom duct extracts $[2,13,17]$ and have been demonstrated to have an important defensive role which has expedited the simplification of the defensive venom of Rhizoconus species [35], in Conus princeps $\alpha \mathrm{D}-\mathrm{PiXXA}$ is a minor component of venom duct extract (Figure 1), which suggests that in this species other types of conotoxins play important roles in defense. Nevertheless, the low abundance of PiXXA in the venom duct extract does not necessarily mean that it is not abundant in the injected venom and, therefore, it might be important for the defensive interactions of this species.

In order to gain insight into the structure-activity relationships of these infrequent, dimeric, vermivorous toxins, we compared the sequences of the $\alpha \mathrm{D}$-CTXs that have been characterized at the electrophysiological level. The multiple alignments of PiXXA with VxXXB, Ms, Cp, and GeXXA (Figure 9) clearly shows that the toxins of the species belonging to the Rhizoconus subgenus 
(vexillum, capitaneus, and mustelinus) are more related to each other than to those from both Strategoconus (generalis) and Ductoconus (princeps). This is not unexpected and has also been observed by Prashanth et al. in a study including species belonging to the Stephanoconus, Strategoconus, Splinoconus, and Elisaconus subgenera in a phylogenetic tree including toxins from six Rhizoconus species [35].

\begin{tabular}{|c|c|}
\hline Ms20.3 & M PKLA VVLLVLLILP LSYFDAAGGQVVQGDRRGNGLARYLQRGDRD - VRECQVNTPGSSW \\
\hline Ms20.3a & M PKLA VVLLVLLILP LSYFDAAGGQVVQGD RRGNGLARYLQRGDRD - VRECQVNTPGSKW \\
\hline Cp20.3 & M PKLA VVLLVLLILP LSYFDAAGGQAVQGD RRGNGLARYLQRGDRE-VQECQVDTPGSSW \\
\hline $\mathrm{VxXXB}$ & M PKLA VVLLV LLILP LSYFDAAGGQAVQGDWRGNR LARDLQRGGRDDES ECI INTRDSPW \\
\hline PixXA & MPKLEMMLLVLLILP LPYFDAAGGQ SVHVD GYGDGLARYL QRGERAVKK TCIRS TPGSNW \\
\hline \multirow[t]{2}{*}{ GeXXA } & M PKQE KMMLVLLILP LPYCNAAGVT TVQWGGHGDGLDRYLQRGVRDIHR PCQSVRPGRVW \\
\hline & 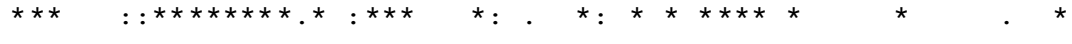 \\
\hline
\end{tabular}

Ms20.3 GKCCMTRMCGTMCCARSGCTCVYHWRRGHGCSCPG

Ms20.3a GKCCMTRMCGTMCCARSGCTCVYHWRRGHGCSCPG

Cp20.3 GKCCMTRMCGTMCCS RSVCT CVYHWRRGHGCSCPG

VXXXB GRCCRTRMCGSMCCP RNGCT CVYHWRRGHGCSCPG

PIXXA GRCCLTKMCHTLCCARSDCT CVYRS GKGHGCSCTS

GeXXA GKCCLTRLCSTMCCARADCTCVYHTWRGHGCSCVM

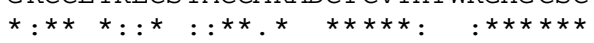

(a)

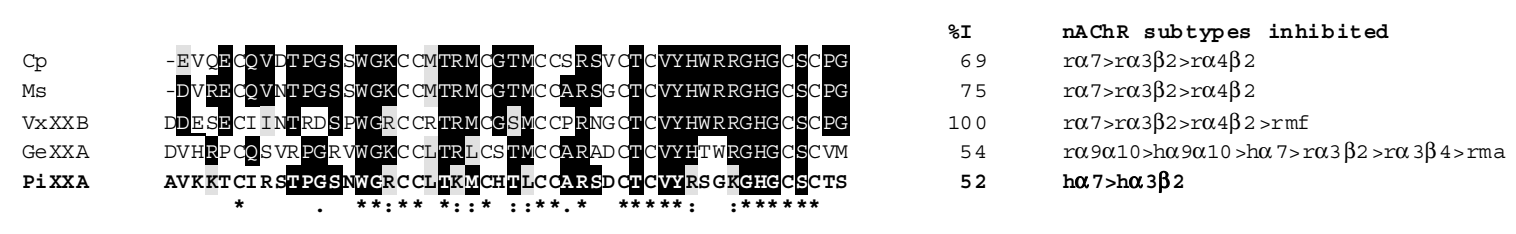

(b)

Figure 9. (a) Sequences of the precursors of PiXXA and of the alphaD-conotoxins whose biological activity has been demonstrated experimentally. (b) Comparison of the $\alpha \mathrm{D}$-CTX that have been characterized electrophysiologically. \%I, percent identity with respect to the first $\alpha \mathrm{D}-\mathrm{CTX}$ studied at this level, $\alpha \mathrm{D}-\mathrm{Vx} X X \mathrm{~B}$ [13]. The prefixes " $\mathrm{r}$ " and " $\mathrm{h}$ " stand for rat and human, respectively. nAChRs: $\mathrm{mf}, \alpha 1 \beta 1 \gamma \delta ; \mathrm{ma}, \alpha 1 \beta 1 \delta \varepsilon$. Cp and Ms, $\alpha \mathrm{D}-\mathrm{Cp}$ (major sequence) and $\alpha \mathrm{D}-\mathrm{Ms}$, respectively [17]. GeXXA, $\alpha \mathrm{D}-\mathrm{GeXXA}$ [2], PiXXA (bold face), $\alpha \mathrm{D}-\mathrm{PiXXA}$ [this work]. Post-translational modifications: O, hydroxy-Pro; $\gamma$, gamma-carboxyglutamic acid. In both panels, positions with identical residues (*) and conserved (:) or semiconserved (.) substitutions are indicated at the bottom of the alignments. In panel B, with the exception of Cys, identical residues present in two or more sequences are highlighted by black background when at least one conserved substitution (highlighted by gray background) is present at the same position.

$\alpha \mathrm{D}-\mathrm{GeXXA}$ is the one toxin that has been tested over $\alpha 9 \alpha 10 \mathrm{nAChRs}$ (rat and human) and shown to be more potent over this subtype than over $\alpha 7$ (human) [2]. Despite $\alpha \mathrm{D}-\mathrm{GeXXA}$ has some residues that are not present in any of the $\alpha \mathrm{D}-\mathrm{CTX}$ from the Rhizoconus species (even as conserved substitutions), such as Val-2, His-3, Asp-33, and Thr-40 (and that shares, as such or as conserved substitutions, with $\alpha \mathrm{D}-\mathrm{PiXXA}$ ), we cannot point to any of these residues as responsible for the highest affinity of $\alpha \mathrm{D}-\mathrm{GeXXA}$ for the $\alpha 9 \alpha 10$ subtype. As mentioned above, the amount of natural toxin prevented testing $\alpha \mathrm{D}-\mathrm{PiXXA}$ over this subtype.

In summary, this work is the first report of $\alpha$ D-CTXs from species of the Eastern Pacific, specifically from the vermivore $C$. princeps from Mexican coasts. Like the $\alpha \mathrm{D}-\mathrm{CTX}$ s from species of the Indo-Pacific (also vermivorous), $\alpha \mathrm{D}-\mathrm{PiXXA}$ has a clear antagonistic effect over $\alpha 7 \mathrm{nAChRs}$ (human). Due to their remarkably different three-dimensional structure with respect to other nAChR-affecting toxins and their allosteric mechanism of action, $\alpha \mathrm{D}$-conotoxins are expected to contribute to our growing knowledge 
of ligand interactions with nAChRs [2]. The isolation of $\alpha$ D-CTXs targeting neuronal h $\alpha 7 \mathrm{nAChRs}$ from barely studied species such as $C$. princeps could provide novel molecular tools and therapeutic agents, or leads for rationally designing them, for the treatment of a range of neurological disorders that involve these receptors [22].

\section{Materials and Methods}

\subsection{Reagents}

Genetic engineering products: Wizard Plus SV Minipreps DNA Purification System was purchased from Promega Corp. (Madison, WI, USA); Not I restriction enzyme from Thermo Fisher Scientific (Waltham, MA, USA), mMESSAGE mMACHINE kit for high yield capped RNA transcription from Ambion Inc. (Austin, TX, USA); QIAquick PCR Purification and RNeasy Mini kits from Qiagen (Hilden, Germany). Gentamycin was obtained from Life Technologies Co. (Grand Island, NY, USA). High Performance Liquid Chromatography (HPLC) reagents: Trifluoroacetic acid (TFA) was acquired from Thermo Scientific (Rockford, IL, USA); HPLC-grade acetonitrile (ACN) from Sigma Chemical Co. (St. Louis, MO, USA). Bradford protein assay kit from Thermo Scientific (Rockford, IL, USA): oxidized insulin B chain, bovine serum albumin (BSA), type I collagenase, and acetylcholine (ACh) from Sigma Chemical Co. (St. Louis, MO, USA). All other reagents were analytical grade.

\subsection{Obtainment of Crude Venom Extract}

C. princeps specimens were captured off the coasts of the Mexican Eastern Pacific Ocean (state of Jalisco) and conserved at $-70^{\circ} \mathrm{C}$. The venom ducts of 35 specimens were isolated and homogenized in $4.0 \mathrm{~mL}$ of $40 \%(v / v)$ ACN in water containing $2.0 \%(v / v)$ TFA. The homogenate was centrifuged at $10,000 \mathrm{~g}$ for $15 \mathrm{~min}$, and the crude venom extract (supernatant) used for fractionation by HPLC as described below. Protein content was analyzed by the Bradford method using BSA as standard [36].

\subsection{Fractionation of the Crude Venom Extract}

Aliquots $(1.5 \mathrm{mg}$ of protein/534 $\mu \mathrm{L})$ of the obtained crude venom extract were centrifuged at $10,000 \mathrm{~g}$ for $15 \mathrm{~min}$ and the supernatant was taken to $5 \mathrm{~mL}$ with Solution A (aqueous solution with $0.1 \%$ $(v / v)$ TFA) before of the fractionation by Reversed Phase-High Performance Liquid Chromatography (RP-HPLC) in a Waters 600 HPLC System (Milford, MA, USA) using a Vydac Peptide \& Protein C18 column (218TP54, $5 \mu \mathrm{m}$ particle size, $4.6 \mathrm{~mm}$ i.d. $\times 250 \mathrm{~mm}$ ). The column was equilibrated at room temperature with Solution A. Fractions of the crude venom extract were eluted with a linear gradient from $0 \%$ to $100 \%(v / v)$ of Solution B $(90 \% \mathrm{ACN}$ in water containing $0.085 \%(v / v)$ TFA), over $200 \mathrm{~min}$, after an isocratic step of $0 \%$ Solution B for $10 \mathrm{~min}$, at a flow rate of $1 \mathrm{~mL} / \mathrm{min}$. The elution profile was monitored at $220 \mathrm{~nm}$. Fractions were quantified by comparison of areas yielded by the HPLC system in comparison with a standard curve of oxidized bovine insulin B chain.

\subsection{Purification of the Active Peptide}

The first step of purification was performed by RP-HPLC using a linear gradient from $10 \%$ to $30 \%$ $(v / v)$ of Solution B, over $200 \mathrm{~min}$, after an isocratic step at 10\% Solution B for $10 \mathrm{~min}$ at a flow rate of $1.0 \mathrm{~mL} / \mathrm{min}$. A second step of purification was done using a linear gradient from $0 \%$ to $20 \%(v / v)$ of Solution B, over $200 \mathrm{~min}$, after an isocratic step at $\%$ Solution B for $10 \mathrm{~min}$ at a flow rate of $0.8 \mathrm{~mL} / \mathrm{min}$ in the same HPLC system. The elution profile was monitored at $220 \mathrm{~nm}$. Fractions were quantified as described above for the crude venom extract.

\subsection{Determination of Electrophysiological Activity on $n A C h R s$}

Ovarian lobes from Xenopus laevis frogs were removed and placed in OR-2 solution ( $82.5 \mathrm{mM}$ $\mathrm{NaCl}, 2.0 \mathrm{mM} \mathrm{KCl}, 1.0 \mathrm{mM} \mathrm{MgCl}_{2} \cdot 6 \mathrm{H}_{2} \mathrm{O}$, and $5 \mathrm{mM}$ HEPES, pH 7.3); then they were defolliculated with $1.25 \mathrm{mg} / \mathrm{mL}$ type 1 collagenase in OR-2 solution for $40 \mathrm{~min}$ at room temperature and slowly 
stired. The Xenopus oocytes were then washed five times with $5 \mathrm{~mL}$ of OR-2 solution. Stage VI oocytes were selected and incubated in ND-96 (96.0 mM NaCl, $2.0 \mathrm{mM} \mathrm{KCl}, 1.0 \mathrm{mM} \mathrm{MgCl} 2 \cdot 6 \mathrm{H}_{2} \mathrm{O}, 1.8 \mathrm{mM}$ $\mathrm{CaCl}_{2} \cdot 2 \mathrm{H}_{2} \mathrm{O}, 5 \mathrm{mM}$ HEPES, pH 7.3)/gentamycin $(8 \mu \mathrm{g} / \mathrm{mL})$ solution, at $15^{\circ} \mathrm{C}$. Oocytes were injected 1 day after harvesting.

cDNA clones encoding neuronal human $\alpha 3$ and $\alpha 7$ and $\beta 2 \mathrm{nAChR}$ subunits were kindly provided by Dr. J. Michael McIntosh (Department of Psychiatry and Department of Biology, University of Utah, Salt Lake City, UT, USA). After amplification, purification, linearization, and purification of linearized cDNAs, cRNA was obtained using the in vitro RNA transcription kit, according to the protocol of the manufacturer. cRNAs were purified and confirmed on 1.5\% agarose/buffer MOPS (MOPS-sodium acetate-EDTA, $\mathrm{pH} 7$ ) gels, and stored at $-80{ }^{\circ} \mathrm{C}$. For expression of neuronal human $\alpha 7$ and $\alpha 3 \beta 2$ at $55.8 \mathrm{ng}$ and $13.3 \mathrm{ng}$ of the corresponding cRNAs, respectively, were injected into each oocyte with a Drummond Nanoject II Auto-Nanoliter injector (Drummond Scientific, Broomall, PA, USA). Each injected oocyte was incubated in ND-96/gentamycin solution at $15^{\circ} \mathrm{C}$ [37]. Oocyte recordings were obtained after $72 \mathrm{~h}$ through day six post-injection.

A two-electrode voltage clamp amplifier was operated (Oocyte Clamp OC-725C, Warner Instruments Corp., Hamden, CT, USA) to measure the effects of C. princeps chromatographic fractions on neuronal human $\alpha 7 \mathrm{nAChRs}$ expressed by Xenopus laevis oocytes and the purified peptide on h $\alpha 7$ and h $\alpha 3 \beta 2 \mathrm{nAChRs} \mathrm{[37].} \mathrm{Resistances} \mathrm{were} \mathrm{2-3} \mathrm{megohm} \mathrm{for} \mathrm{voltage} \mathrm{and} \mathrm{0.5-1.0} \mathrm{megohm}$ for current electrodes. The membrane potential was clamped at $-70 \mathrm{mV}$. The oocytes were kept in a chamber (volume $\approx 40 \mu \mathrm{L}$ ) with ND-96 solution at a constant rate of $1 \mathrm{~mL} / \mathrm{min}$. Three microlitres of the fraction or purified peptide $(1.0 \mu \mathrm{g} / \mu \mathrm{L})$ was directly pipetted into the static chamber for $5 \mathrm{~min}$ prior to exposure to 1-s pulses of $100 \mu \mathrm{M}$ ACh in ND-96 solution. Three $\mu \mathrm{g}$ of chromatographic fractions or purified toxin was used for a final concentration of $0.07 \mu \mathrm{g} / \mu \mathrm{L}$. The amount of sample was defined considering a peptide of approximately $3 \mathrm{kDa}$ and molarity of $23.3 \mu \mathrm{M}$, in order to be able to detect toxins with low affinity for human $\mathrm{AAChR}$. Data acquisition was automatically controlled by a home-made virtual instrument constructed with the graphical programming language LabView 8.6 (National Instruments, Austin, TX, USA). All recordings were made at room temperature. The average of seven control ACh-induced responses just preceding a test response was used to obtain the $\%$ inhibition. At least three oocytes were assessed in each assay $(n \geq 3)$.

The concentration-response curve for the purified toxin was determined with $0.1,0.2,0.3,1.0$, 3.0, 6.0, and $10.0 \mu \mathrm{g}$ (which correspond to concentrations of $0.2,0.4,0.6,2.2,6.5,13.0$, and $21.7 \mu \mathrm{M}$ ). All electrophysiological data were pooled ( $n=2-4$ oocytes for each data point).

\subsection{Determination of Molecular Mass and Amino Acid Sequence of the Purified Peptide}

The molecular mass of one native purified peptide (F7-3, $2.0 \mu \mathrm{g}$ dissolved in $10 \mu \mathrm{L}$ of $0.1 \%$ aqueous formic acid) was determined by a LC-MS system composed by a nano-flow liquid chromatographer Dionex 3000 and a hybrid Orbitrap Velos mass spectrometer with nano-electrospray ion source, both from Thermo-Fisher (San Jose, CA, USA). Calibration of the mass spectrometer was carried out using Calmix solution consisting of 10 different calibrants allowing measurements with accuracies better than 5 parts per million. The nano-flow chromatographic system was operated at $350 \mathrm{~nL} / \mathrm{min}$, using an isocratic gradient of $50 \%$ Solvent B ( $0.1 \%$ acetic acid in ACN; Solvent A, $0.1 \%$ acetic acid in water) for 30 min. A micro-needle (New Objective, Woburn, MA, USA) was used in the nano-electrospray ionization source operating with $2.0 \mathrm{kV}$ of spray voltage.

The amino acid sequence of the purified peptide was determined by automated Edman degradation. A PPSQ-31A Protein Sequencer (Shimadzu Scientific Instruments, Columbia, MD, USA) was used. The purified peptide (F7-3, $5 \mu \mathrm{g}$ ) was sequenced without reduction and alkylation; the sample was dissolved in $5 \mu \mathrm{L}$ of $60 \%(v / v)$ aqueous ACN containing $1.0 \%$ acetic acid. An aliquot of $4 \mu \mathrm{L}$ was taken and diluted with $10 \mu \mathrm{L}$ of $37 \%$ aqueous ACN. The mixture was then loaded onto a TFA-treated glass fiber disk (073-04171, Wako Pure Chemical Industries, Ltd., Osaka, Japan) previously treated with 
polybrene (Sigma-Aldrich Corp., St. Louis, MO, USA) according to manufacturer's protocol. The Glass Fiber Disk protocol was used for 32 cycles.

\subsection{Similarity Search and Sequence Alignment}

Protein-protein BLAST, BLASTP 2.9.0+ [38], was used to search the $\mathrm{nr}$ (Non-redundant protein sequences) database, with Organism $=$ Conus (taxid:6490), and the default parameters.

Clustal W 2.1 [39] in the GenomeNet of the Kyoto University Bioinformatics Center [40] was used for multiple sequence alignment, using the default parameters, except that, in order to obtain the most accurate results, the option for Pairwise Alignment was changed from the default (FAST/APPROXIMATE) to SLOW/ACCURATE.

\subsection{Statistical Analysis}

All analyses were carried out at least in triplicate, mean values \pm standard deviations were reported. Differences were statistically accepted at $\mathrm{P}<0.05$. The half-maximal inhibitory concentration $\left(\mathrm{IC}_{50}\right)$ value was determined using Prism 2.0 (GraphPad Software, San Diego, CA, USA), by fitting the data obtained from the concentration-response relationship to the equation (1):

$$
R=R_{\min }+\left[\left(R_{\max }-R_{\min }\right) /\left(1+10 \log \left(I C_{50}-C\right)\right)\right]
$$

where $R$ is the response (percent inhibition) at a given concentration (C) of $\alpha \mathrm{D}-\mathrm{PiXXA}, R_{\min }$ is the minimum response, $R_{\max }$ is the maximum response, and $I C_{50}$ is the concentration that produces $50 \%$ of $R_{\max }$. Standard errors of the mean were used for this calculation.

Author Contributions: M.B.A. conceived of the project. A.C.H.-S. and M.B.A. wrote the article. A.C.H.-S., A.F., F.Z., and C.V.F.B. performed the experiments. A.C.H.-S., M.B.A., F.Z., and C.V.F.B. analyzed the results. J.E.M.-M. and V.L.-J. coordinated the collection and taxonomical work. E.L.-V. provided the cDNAs of the nAChRs subunits, conceptual and technical advice, and comments on the manuscript. M.C.J. validated experimental results related to the sequence of the toxin and reviewed and commented on the manuscript. All authors have read and approved the final manuscript.

Funding: This work was supported by the Universidad Nacional Autónoma de México Institutional budget to the Laboratorio de Neurofarmacología Marina, Instituto de Neurobiología (M.B.A.), by the Secretaría de Educación Pública, Programa para el Desarrollo Profesional Docente, para el tipo superior (SEP-PRODEP), for the Red Temática de Colaboración Académica "Estudio de los moluscos marinos de interés farmacológico", Project "Diagnóstico de la fauna de Gasterópodos venenosos del Pacífico mexicano con potencial uso farmacológico" (739-CA-UDG) (J.E.M.M.). This work was also supported by Grant IN208617 from the Programa de Apoyo a Proyectos de Investigación e Innovación Tecnológica, Universidad Nacional Autónoma de México (M.B.A.)

Acknowledgments: A.C.H.S. was supported by a postdoctoral fellowship (CVU 229186) from the National Council of Science and Technology of Mexico (CONACYT). We thank Lourival D. Possani Postay (Departmento de Medicina Molecular y Bioprocesos, Instituto de Biotecnología, Universidad Nacional Autónoma de México) for providing access to the protein sequencer. We thank I.C. Lorena Hernández Orihuela and Biol. Erika Patricia Meneses Romero from the Laboratorio Universitario de Proteómica, Instituto de Biotecnología, Universidad Nacional Autónoma de México for the mass spectrometry analysis. We thank Doju Yoshikami for sharing with us his software developed in LabView. We also thank Anaid Antaramian Salas and M.S. Adriana González Gallardo from the Unidad de Proteogenómica, Instituto de Neurobiología, Universidad Nacional Autónoma de México for providing LB medium with antibiotics in Petri dishes and access to the NanoDrop spectrophotometer.

Conflicts of Interest: The authors declare no conflict of interest.

\section{References}

1. Hopping, G.; Wang, C.I.A.; Hogg, R.C.; Nevin, S.T.; Lewis, R.J.; Adams, D.J.; Alewood, P.F. Hydrophobic residues at position 10 of $\alpha$-conotoxin PnIA influence subtype selectivity between $\alpha 7$ and $\alpha 3 \beta 2$ neuronal nicotinic acetylcholine receptors. Biochem. Pharmacol. 2014, 91, 534-542. [CrossRef] [PubMed]

2. Xu, S.; Zhang, T.; Kompella, S.N.; Yan, M.; Lu, A.; Wang, Y.; Shao, X.; Chi, C.; Adams, D.J.; Ding, J.; et al. Conotoxin $\alpha$ D-GeXXA utilizes a novel strategy to antagonize nicotinic acetylcholine receptors. Sci. Rep. 2015, 5, 14261. [CrossRef] [PubMed] 
3. Giribaldi, J.; Dutertre, S. $\alpha$-Conotoxins to explore the molecular, physiological and pathophysiological functions of neuronal acetylcholine receptors. Neurosci. Lett. 2017, 679, 24-34. [CrossRef] [PubMed]

4. Abraham, N.; Lewis, R.J. Review-Neuronal nicotinic acetylcholine receptor modulators from cone snails. Mar. Drugs 2018, 16, 208. [CrossRef] [PubMed]

5. Wang, S.; Zhao, C.; Liu, Z.; Wang, X.; Liu, N.; Du, W.; Dai, Q. Structural and functional characterization of a novel $\alpha$-conotoxin Mr1.7 from Conus marmoreus targeting neuronal nAChR $\alpha 3 \beta 2, \alpha 9 \alpha 10$ and $\alpha 6 / \alpha 3 \beta 2 \beta 3$ subtypes. Mar. Drugs 2015, 13, 3259-3275. [CrossRef] [PubMed]

6. Prashanth, J.R.S.; Dutertre, S.; Lewis, R.J. Pharmacology of predatory and defensive venom peptides in cone snails. Mol. Biosyst. 2017, 13, 2453-2465. [CrossRef] [PubMed]

7. Dutertre, S.; Jin, A.H.; Vetter, I.; Hamilton, B.; Sunagar, K.; Lavergne, V.; Dutertre, V.; Fry, B.G.; Antunes, A.; Venter, D.J.; et al. Evolution of separate predation- and defence-evoked venoms in carnivorous cone snails. Nat. Commun. 2014, 5, 3521. [CrossRef] [PubMed]

8. Kumar, P.S.; Kumar, D.S.; Umamaheswari, S. A perspective on toxicology of Conus venom peptides. Asian Pac. J. Trop. Med. 2015, 8, 337-351. [CrossRef]

9. Akondi, K.B.; Muttenthaler, M.; Dutertre, S.; Kaas, Q.; Craik, D.J.; Lewis, R.J.; Alewood, P.F. Discovery, synthesis, and structure-activity relationships of conotoxins. Chem. Rev. 2014, 114, 5815-5847. [CrossRef]

10. Lebbe, E.K.; Peigneur, S.; Wijesekara, I.; Tytgat, J. Conotoxins targeting nicotinic acetylcholine receptors: An overview. Mar. Drugs 2014, 12, 2970-3004. [CrossRef]

11. Olivera, B.M.; Quik, M.; Vincler, M.; McIntosh, J.M. Subtype-selective conopeptides targeted to nicotinic receptors: Concerted discovery and biomedical applications. Channels 2008, 2, 143-152. [CrossRef] [PubMed]

12. Dutertre, S.; Nicke, A.; Tsetlin, V.I. Nicotinic acetylcholine receptor inhibitors derived from snake and snail venoms. Neuropharmacology 2017, 127, 196-223. [CrossRef] [PubMed]

13. Loughnan, M.; Nicke, A.; Jones, A.; Schroeder, C.I.; Nevin, S.T.; Adams, D.J.; Alewood, P.F.; Lewis, R.J. Identification of a novel class of nicotinic receptor antagonists: Dimeric conotoxins VxXIIA, VxXIIB, and VxXIIC from Conus vexillum. J. Biol. Chem. 2006, 281, 24745-24755. [CrossRef] [PubMed]

14. Morales-González, D.; Flores-Martínez, E.; Zamora-Bustillos, R.; Rivera-Reyes, R.; Michel-Morfín, J.E.; Landa-Jaime, V.; Falcón, A.; Aguilar, M.B. Diversity of A-conotoxins of three worm-hunting cone snails (Conus brunneus, Conus nux, and Conus princeps) from the Mexican Pacific coast. Peptides 2015, 68, 25-32. [CrossRef] [PubMed]

15. Mass Spectrometry and Biotechnology Resource of IonSourcesm Mass Spectrometry Educational Resource Website. Available online: http://www.ionsource.com/programs/PEPCALC.HTM (accessed on 21 May 2019).

16. Loughnan, M.L.; Nicke, A.; Lawrence, N.; Lewis, R.J. Novel $\alpha$ D-conopeptides and their precursors identified by cDNA cloning define the D-conotoxin superfamily. Biochemistry 2009, 48, 3717-3729. [CrossRef] [PubMed]

17. Kauferstein, S.; Kendel, Y.; Nicke, A.; Coronas, F.I.V.; Possani, L.D.; Favreau, P.; Krizaj, I.; Wunder, C.; Kauert, G.; Mebs, D. New conopeptides of the D-superfamily selectively inhibiting neuronal nicotinic acetylcholine receptors. Toxicon 2009, 54, 295-301. [CrossRef] [PubMed]

18. Jeziorski, M.C.; Michel-Morfín, J.E.; Landa-Jaime, V.; Falcón, A.; Varela-Echavarría, A.; Ayala-Sumuano, J.T.; Aguilar, M.B. Transcriptomic analysis of the venom gland of the cone snail Conus princeps from the Mexican Pacific. In Proceedings of the 12th Congress of the Pan-American Section of the International Society on Toxinology, Miami Beach, FL, USA, 18-23 September 2016.

19. Bernáldez, J.; Jiménez, S.; González, L.J.; Noda, F.J.; Soto, E.; Salceda, E.; Chávez, D.; Aguilar, M.B.; Licea-Navarro, A. A new member of gamma-conotoxin family isolated from Conus princeps displays a novel molecular target. Toxins 2016, 8, 39. [CrossRef] [PubMed]

20. Hernández-Sámano, A.C.; Falcón, A.; Batista, C.V.F.; Zamudio, F.; Michel-Morfín, J.E.; Landa-Jaime, V.; López-Vera, E.; Martínez-Romero, G.M.; Aguilar, M.B. $\gamma$-Conotoxin PiVIIA from Conus princeps venom potentiates h $\alpha 3 \beta 2$ nicotinic acetylcholine receptors. In Proceedings of the Invertebrate Neuropeptide Conference 2019, Campeche, Mexico, 17-21 February 2019.

21. Zamora-Bustillos, R.; Rivera-Reyes, R.; Aguilar, M.B.; Michel-Morfín, E.; Landa-Jaime, V.; Falcón, A.; Heimer, E.P. Identification, by RT-PCR, of eight novel $\mathrm{I}_{2}$-conotoxins from the worm-hunting cone snails Conus brunneus, Conus nux, and Conus princeps from the eastern Pacific (Mexico). Peptides 2014, 53, $22-29$. [CrossRef] [PubMed]

22. Bertrand, D.; Lee, C.H.; Flood, D.; Marger, F.; Donnelly-Roberts, D. Therapeutic potential of $\alpha 7$ nicotinic acetylcholine receptors. Pharmacol. Rev. 2015, 67, 1025-1073. [CrossRef] [PubMed] 
23. Armishaw, C.; Jensen, A.A.; Balle, T.; Clark, R.J.; Harpsøe, K.; Skonberg, C.; Liljefors, T.; Strømgaard, K. Rational design of $\alpha$-conotoxin analogues targeting $\alpha 7$ nicotinic acetylcholine receptors. J. Biol. Chem. 2009, 284, 9498-9512. [CrossRef] [PubMed]

24. Daly, N.L.; Callaghan, B.; Clark, R.J.; Nevin, S.T.; Adams, D.J.; Craik, D.J. Structure and activity of $\alpha$-conotoxin PeIA at nicotinic acetylcholine receptor subtypes and $\mathrm{GABA}_{\mathrm{B}}$ receptor-coupled N-type calcium channels. J. Biol. Chem. 2011, 286, 10233-10237. [CrossRef] [PubMed]

25. Conoserver Website. Available online: http://www.conoserver.org/ (accessed on 12 May 2019).

26. Ellison, M.; Gao, F.; Wang, H.L.; Sine, S.M.; Olivera, B.M. $\alpha$-conotoxins ImI and ImII target distinct regions of the human alpha7 nicotinic acetylcholine receptor and distinguish human nicotinic receptor subtypes. Biochemistry 2004, 43, 16019-16026. [CrossRef] [PubMed]

27. Franco, A.; Pisarewicz, K.; Moller, C.; Mora, D.; Fields, G.B.; Mari, F. Hyperhydroxylation: A new strategy for neuronal targeting by venomous marine molluscs. Prog. Mol. Subcell. Biol. 2006, 43, 83-103. [PubMed]

28. Inserra, M.C.; Kompella, S.N.; Vetter, I.; Brust, A.; Daly, N.L.; Cuny, H.; Craik, D.J.; Alewood, P.F.; Adams, D.J.; Lewis, R.J. Isolation and characterization of $\alpha$-conotoxin LsIA with potent activity at nicotinic acetylcholine receptors. Biochem. Pharmacol. 2013, 86, 791-799. [CrossRef] [PubMed]

29. Yu, J.; Zhu, X.; Zhang, L.; Kudryavtsev, D.; Kasheverov, I.; Lei, Y.; Zhangsun, D.; Tsetlin, V.; Luo, S. Species specificity of rat and human $\alpha 7$ nicotinic acetylcholine receptors towards different classes of peptide and protein antagonists. Neuropharmacology 2018, 139, 226-237. [CrossRef] [PubMed]

30. Azam, L.; McIntosh, J.M. Molecular basis for the differential sensitivity of rat and human $\alpha 9 \alpha 10 \mathrm{nAChRs}$ to $\alpha$-conotoxin RgIA. J. Neurochem. 2012, 122, 1137-1144. [CrossRef] [PubMed]

31. Yu, R.; Kompella, S.N.; Adams, D.J.; Craik, D.J.; Kaas, Q. Determination of the $\alpha$-conotoxin Vc1.1 binding site on the $\alpha 9 \alpha 10$ nicotinic acetylcholine receptor. J. Med. Chem. 2013, 56, 3557-3567. [CrossRef] [PubMed]

32. Kompella, S.N.; Cuny, H.; Hung, A.; Adams, D.J. Molecular basis for differential sensitivity of $\alpha$-conotoxin RegIIA at rat and human neuronal nicotinic acetylcholine receptors. Mol. Pharmacol. 2015, 88, 993-1001. [CrossRef]

33. Puillandre, N.; Bouchet, P.; Duda, T.F., Jr.; Kauferstein, S.; Kohn, A.J.; Olivera, B.M.; Watkins, M.; Meyer, C. Molecular phylogeny and evolution of the cone snails (Gastropoda, Conoidea). Mol. Phylogenet. Evol. 2014, 78, 290-303. [CrossRef]

34. Mebs, D.; Kordis, D.; Kendel, Y.; Kauferstein, S. The evolution of $\alpha$ D-conopeptides targeting neuronal nicotinic acetylcholine receptors. Acta Chim. Slov. 2011, 58, 730-734.

35. Prashanth, J.R.; Dutertre, S.; Jin, A.H.; Lavergne, V.; Hamilton, B.; Cardoso, F.C.; Griffin, J.; Venter, D.J.; Alewood, P.F.; Lewis, R.J. The role of defensive ecological interactions in the evolution of conotoxins. Mol. Ecol. 2016, 25, 598-615. [CrossRef] [PubMed]

36. Bradford, M.M. A rapid and sensitive method for the quantitation of microgram quantities of protein utilizing the principle of protein-dye binding. Anal. Biochem. 1976, 72, 248-254. [CrossRef]

37. Cartier, G.E.; Yoshikami, D.; Gray, W.R.; Luo, S.; Olivera, B.M.; McIntosh, J.M. A new $\alpha$-conotoxin which targets $\alpha 3 \beta 2$ nicotinic acetylcholine receptors. J. Biol. Chem. 1996, 271, 7522-7528. [CrossRef] [PubMed]

38. Altschul, S.F.; Wootton, J.C.; Gertz, E.M.; Agarwala, R.; Morgulis, A.; Schäffer, A.A.; Yu, Y.K. Protein database searches using compositionally adjusted substitution matrices. FEBS J. 2005, 272, 5101-5109. [CrossRef] [PubMed]

39. Larkin, M.A.; Blackshields, G.; Brown, N.P.; Chenna, R.; McGettigan, P.A.; McWilliam, H.; Valentin, F.; Wallace, I.M.; Wilm, A.; Lopez, R.; et al. Clustal W and Clustal X version 2.0. Bioinformatics 2007, 23, 2947-2948. [CrossRef] [PubMed]

40. GenomeNet of the Kyoto University Bioinformatics Center. Available online: https://www.genome.jp/toolsbin/clustalw (accessed on 12 May 2019).

(C) 2019 by the authors. Licensee MDPI, Basel, Switzerland. This article is an open access article distributed under the terms and conditions of the Creative Commons Attribution (CC BY) license (http://creativecommons.org/licenses/by/4.0/). 